\title{
EGYPTIAN FRACTIONS
}

\section{Mina B. Abd-el-Malek*}

\begin{abstract}
Ancient Egyptian hieroglyphics inform us much about the life of the people of ancient Egypt, including their knowledge in mathematics. The Rhind Mathematical Papyrus, and many others, presents to us their basic number system which is very similar to what we have except in one way which is their concept of fractions.

In fact the ancient Egyptians had a way of writing numbers in so many forms, but what recorded in their papyrus was limited. To represent the fraction $1 / 9$, say, they would simply use the symbol for 9 , and then place another symbol on top of it takes the oval form which represents the mouth in the ancient Egyptian alphabet. In general, the reciprocal of an integer " $n$ " was written in the same way. They had no other way of writing fractions, except for special symbols for $1 / 2,1 / 4,1 / 8,1 / 16,1 / 32,1 / 64$, and 2/3 that were modified over different Kingdoms.
\end{abstract}

* Department of Engineering Mathematics and Physics, Faculty of Engineering, Alexandria University, Alexandria, Egypt. 
The study of the properties of Egyptian fractions falls, nowadays, into what we call the area of number theory.

In this paper, we will present some of the problems concerning Egyptian fractions as well as propose some explanations that forced the ancient Egyptians to use the Egyptian fractions, and at the end present one of the applications of the fractions that was found in the symbol of Horus - eye.

\section{Introduction}

When we use non-integer or fractional numbers today in the field of mathematics, there are two ways for presenting these numbers: as fractions (ratios of two integer numbers) such as $2 / 7$, and decimal numbers such as 0.285714 . Computers use binary versions of either of these two representations. But in fact these are not the only possibilities. The other method can be found in the surviving documents of the ancient Egyptians. In their way of presentation, instead of writing down a single fraction, they wrote the fraction as a sum of several distinct unit fractions, each having numerator unity. Therefore, for example, instead of writing the fraction $2 / 7$, they wrote it as $1 / 4+1 / 28$ (using the hieroglyphics numerals).

To write the unit fractions used the Egyptian fraction notation, in hieroglyph script, the Egyptians placed the hieroglyph "er", "[one] among" or possibly "re", mouth, above a number to represent the reciprocal of that number. Similarly in hieratic script they drew a line above the letter representing the number.

The Egyptians had special symbols for $1 / 2,2 / 3$, and $3 / 4$ that were used to reduce the size of numerators greater than $1 / 2$ when such numbers were converted to an Egyptian fraction series.

The Egyptians also used an alternative notation modified from the Old Kingdom and based on the parts of the Eye of Horus to denote a special set of fractions of the form $1 / 2 \mathrm{k}$ (for $\mathrm{k}=1,2, \ldots, 6)$, that is, dyadic rational numbers. These "Horus - Eye fractions" were used in 
the Middle Kingdom in conjunction with the later notation of Egyptian fractions to subdivide a hekat, the primary ancient Egyptian volume measure for grain, bread, and other small quantities of volume, the subject of the Akhmim Wooden Tablet. If any remainder was left after expressing a quantity in Eye of Horus fractions of a hekat, the remainder was written using the regular Egyptian fraction notation as multiples of a ro, a unit equal to 1/320 of a hekat.

Typical of symbolism is denoting "the unknown" by " $x$ ", as we use nowadays in mathematics. We know from Ancient Egyptian hieroglyphs on clay or papyrus that ancient Egyptian priests, in their rhetorical algebra (wherein the problem was stated in words of the language of the ancient mathematician), used the word "aha" meaning "heap" or "set" for the unknown.

\section{What is Egyptian fraction?}

An Egyptian fraction is a sum of distinct unit fractions, i.e. fraction whose numerators are equal to "1", whose denominators are positive integers, and all the denominators differ from each other.

Hence the Egyptian fraction is such as: $\frac{1}{2}+\frac{1}{3}+\frac{1}{16}+\frac{1}{53}+\ldots$

\section{Symbols of Numbers and Fractions in Ancient Egypt}

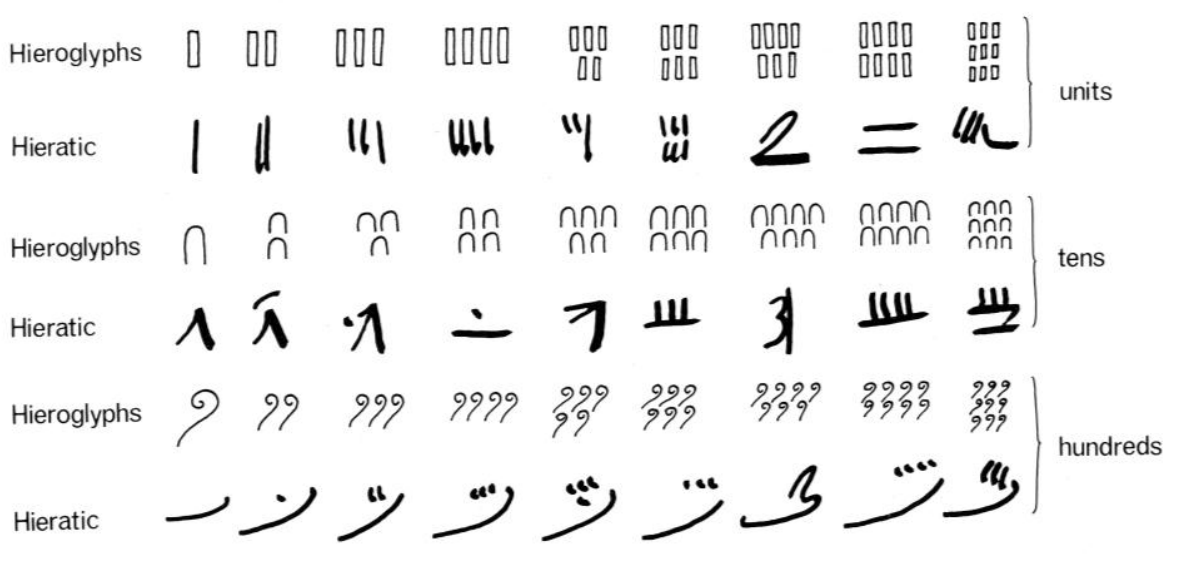

Figure 1. Ancient Egyptian Numerals.[4] 


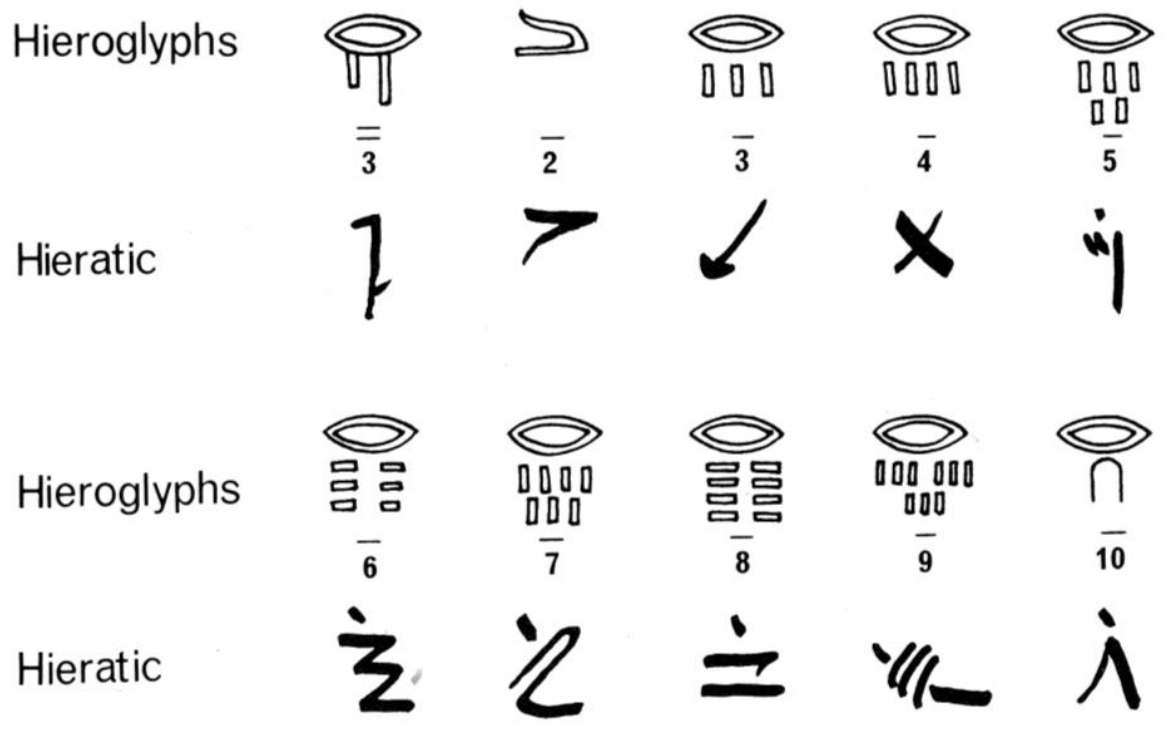

Figure 2. Ancient Egyptian Fractions (Old Kingdom).[4]

Egyptian fraction notation was developed in the Middle Kingdom of Egypt (2080 - 1640 B. C.).

4. Six early texts in which Egyptian fractions appear were:

(1) The Egyptian Mathematical Leather Roll (EMLR), is a $10 \times 17$ inch leather roll, written by an unknown student scribe before 1800 B.C. The EMLR was discovered together with the Rhind Mathematical Papyrus (RMP), in the ruins of the Ramesseum at Thebs in 1855 . It cites six methods to convert $1 / \mathrm{p}$ and $1 / \mathrm{pq}$ rational numbers to Egyptian fraction. The first five multiples of $3,4,5,7$, and 25 . The sixth is an ordinary from $1=1 / 2+1 / 3+1 / 6$. It was purchased by Alexander Henry Rhind (1833 - 1863) in 1858, and then sent to the British Museum in 1864.

(2) The Rhind Mathematical Papyrus (RMP), written by Ahmes in 1650 B.C., that is why sometimes is called Ahmes Papyrus, and its $2 / \mathrm{n}$ table. The $2 / \mathrm{n}$ table extended two EMLR conversion methods to convert $2 / \mathrm{p}$ and $2 / \mathrm{pq}$ fractions to optimal Egyptian 
fraction series. Ahmes used a third method (rediscovered by F. Hultsch in 1895, known today among the mathematicians, of the theory of numbers as the Hultsch - Bruins method) to convert 2/p to optimal Egyptian fraction series. The Rhind Mathematical Papyrus introduced improved ways of writing Egyptian fractions[1].

In 1877, Professor A. Eisenlohr published the first translation of the RMP into a modern language, in his book Ein matematisches handbuch der älten Ägypter (Papyrus Rhind der British Museum), übersetzt und erklärt. T.E. Peet [2] issued an English edition in 1923.

In 1975, Gillings studied the relation between the EMLR and the RAMP Recto [3], and he found that the EMLR stood roughly in a similar relation to the RMP, and particularly the Recto thereof, as say, a modern log book would stand in relation to a mathematical text book, that is, an adjunct to it, for simplifying and reducing calculations, albeit not by any means as detailed or as thorough. But it could have, and might have been, had it been put through a second revised and more detailed program, by the scribe who prepared it.

(3) The Moscow Mathematical Papyrus (MMP), as called Golenišcev Mathematical Papyrus. Its first owner was the Egyptologist Vladimir Golenišcev (1856 - 1947). It is located in the Pushkin State Museum of Fine Arts in Moscow.

(4) The Reisner Papyrus (RP), housed in Boston. Found in 1904 by George Andrew Reisner (1867-1942). It dates to the 1800 B. C. It consists of four fragments of rolls containing calculations of volumes of Egyptian temples. Gillings correctly showed that the Reisner Papyri divided worker digging rated by 10 . The raw data actually follows a quotient and remainder structure. The quotient appeared as an integer, and the remainder appeared as an exact Egyptian fraction series.

(5) The Kahun Papyrus (KP) discussing mathematical and medical topics. Was discovered by Flinders Petrie in 1889 in the Middle Kingdom town of El-Lahun (Kahun), and are kept at the University College London. Most of the texts are dated to $1825 \mathrm{~B}$. 
C. One fragment of the KP begins with a traditional RMP 2/n table, a Middle Kingdom scribe's method of defining arithmetic skills related to writing rational numbers in exact unit fraction series. The KP $2 / n$ table offers an abbreviated version of a $2 / n$ table compared to the longer set of 51 rational number terms written as unit fraction series found in the Rhind Mathematical Papyrus (RMP). Considering the KP's central arithmetic topic, arithmetic progressions, most likely the highest form of Egyptian arithmetic, and the scribe defined a 10-term arithmetic progression, summed to 100 , with a difference of $5 / 6$. The KP method detailed an arithmetic progression, a form of mathematics that was also discussed in two RMP problems.

(6) The Akhmim Wooden Tablet (AWT): dates to 2000 B.C., $12^{\text {th }}$ dynasty. It is hosted in Egyptian Museum in Cairo, Egypt. It is dimension $46.5 \times 26 \mathrm{~cm}$. The document was reported in 1901, and first analyzed and published in 1906, by Georges Emile Daressy (1864 - 1938). The first half of the tablet details five divisions of a hekat, partitioned from its unity (64/64), by 3, 7, 10, 11 and 13 . The second half of the document proved the correctness of the five division answers by multiplying the two-part quotient and remainder answer by its respective divisor (3, 7, 10, 11 and 13). In 2002, the Czech Egyptologist Hana Vymazalová (born in 1978), gained a fresh copy of the text from the Cairo Museum, and confirmed that all five two-part answers were correctly returned to the initial (64/64) unity value by the scribe. The proof that all five AWT divisions had been exact was suspected by Daressy, but was not proven in 1906. Typographical errors in Daressy's copy of two problems, the division by 11 and 13 data, were corrected by Hana Vymazalová.

\section{The Rhind Mathematical Papyrus "RMP"}

One of the papyrus scrolls, discovered in a tomb in Thebes, was brought by a 25 year old Scottish lawyer and Egyptologist, Alexander Henry Rhind at a market in Luxor, Egypt, in 1858. After his death at the age of 30, the scroll found its way to the British Museum in 
London in 1864 and remained there ever since, being referred to as the Rhind Mathematical Papyrus (or RMP for short) [4].

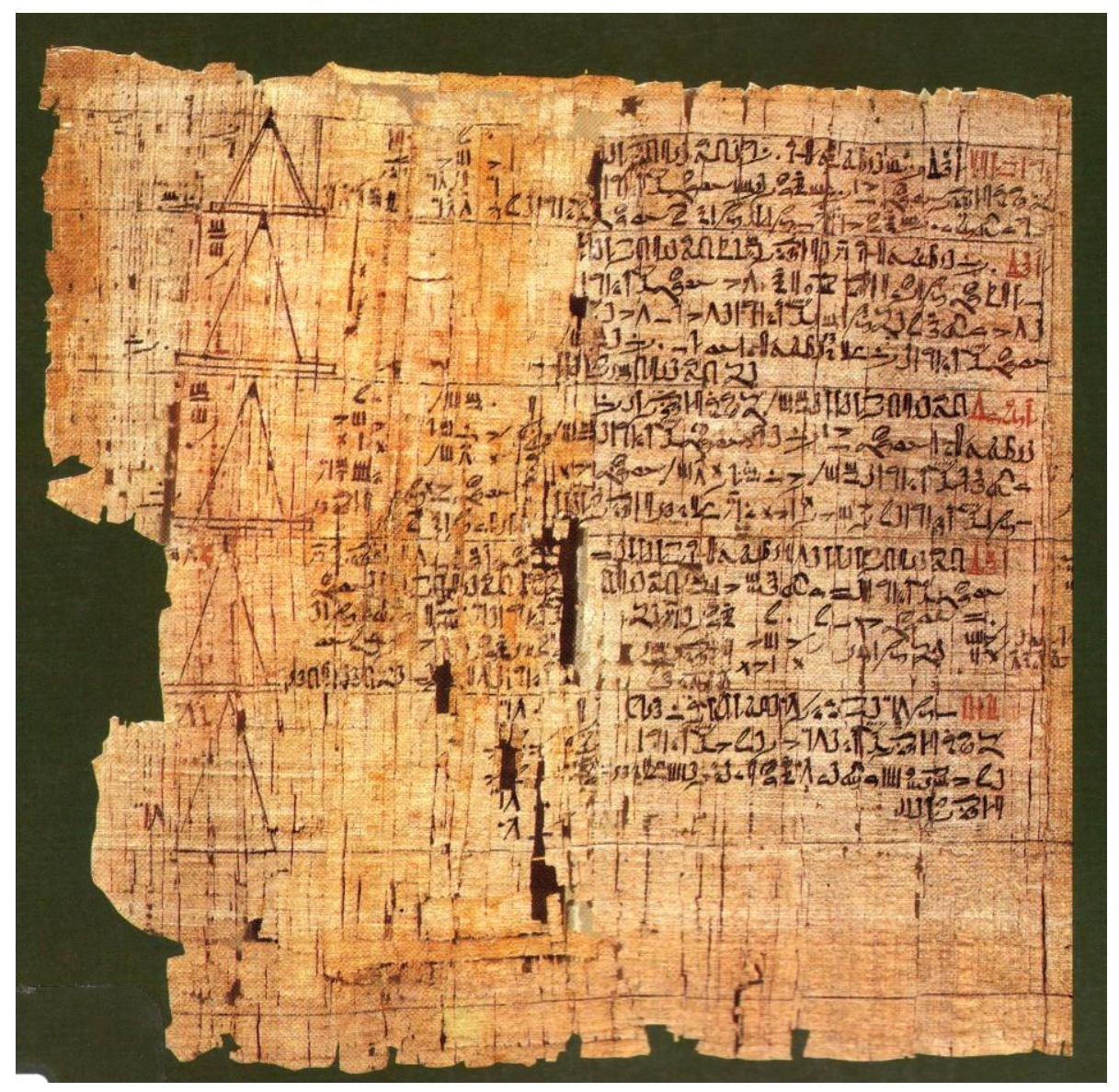

Figure 3. Page of Rhind Papyrus.[4]

\subsection{What did the RMP say?}

It starts off by saying that the scribe "Ahmes" is writing it about 1600 B.C. but he had copied it from "Ancient Writings" so it probably, according to R. Knott estimation" goes back to at least 2000 B.C. and probably further. 
Large part of RMP has applications in astronomy. Also, calculations were needed for geometry and for building and for accounting.

The most interesting point, according to Gillings [5], is that a computer programme was devised in 1967 and run on a KDF-9 machine to calculate all possible unit fractions dividing 2 by odd numbers from 3 to 101 to compare them with the scribe's choice. After 5 hours of extensive computation, among the 22295 different decompositions produced, and considering that there was a time span of almost 4000 years, the computer did not find a decomposition superior to that given by the scribe!! Scientists came to conclusion that Ahmes results were the best in terms of minimality and optimality.

\subsection{Classifications of the RMP problems:}

Problems 7-20: are problems in multiplication that consist of two groups. In the first the multiplier is $1 \frac{1 / 2}{1 / 4}$ and in the second, $12 / 31 / 3$. Problems 7 and 9-15 belong to the first group and problems 8 and 1620 to the second.

Problems 24-38: are all essentially problems in division by a fractional expression. The first eleven of these problems (24-34) are sometimes called "aha" or quantity problems because they nearly all begin with the word "aha" and use this word to denote the result of their calculations. Problems 35, 37, and 38 the quantity is a measure of grain. In 36 the word for the measure is omitted and the problem by itself is a purely numerical one.

Problem 39: is also a division problem, but it is simply to divide 100 loaves among 10 men, 50 among 6 , and 50 among 4 .

Problem 40: deals with the distribution of loaves in arithmetical progression such that the two smallest shares amount to $1 / 7$ of the three largest shares.

Problem 62: is about a bag with pieces of gold, silver, and lead in it. The meaning is not very clear, but the numerical problem is simple. 
Problem 63: is exactly similar to problem (62). 700 loaves are to be divided among four men in the proportion of the numbers $2 / 3,1 / 2,1 / 3$, and $1 / 4$.

Problem 64: requires to divide 10 hekat of barley between 10 men with a common difference equal to the Horus - eye fraction of $1 / 8$ hekat.

Problem 65: 100 loaves are to be divided among 10 men with three getting double portions.

Problem 66: an amount of fat is given as required for a year, to find how much that is for a day.

Problem 67: required to find bow many cattle there are in a herd when $1 / 61 / 18$ of them makes 70 , the number due as tribute to the owner. It is similar to problems $35-38$.

Problems 69-78: have to do with the relative values of certain amounts of food or drink, the amount of grain in a unit of food or drink, and the amount of food or drink that can be made from a unit measure of grain.

Problem 68: 100 hekat of grain are to be distributed to four overseers, the number of men in their gangs being $12,8,6$, and 4 , respectively.

Problems involving arithmetical and geometrical progression: problems 40 and 64 involve arithmetical progression, while problem 79 involves geometrical progression.

\subsection{The Rhind $2 / \mathrm{n}$ table}

This table found on the RMP contains a list of Egyptian fractions used for $2 / n$ where "n" is an odd number from 3 to 101 . 


\begin{tabular}{|c|c|c|c|c|c|c|c|}
\hline \multicolumn{2}{|c|}{ Fraction 2/ } & \multicolumn{3}{|c|}{ Divisors of Expansion } & \multirow{2}{*}{$\frac{\text { Fraction } 2 /}{4}$} & \multicolumn{2}{|c|}{ Divisors of Expansion } \\
\hline 5 & 3 & 15 & & 7 & & 28 & \\
\hline 9 & 6 & 18 & & 11 & 6 & 66 & \\
\hline 13 & 8 & 52 & 104 & 15 & 10 & 30 & \\
\hline 17 & 12 & 51 & 68 & 19 & 12 & 76 & 114 \\
\hline 21 & 14 & 42 & & 23 & 12 & 276 & \\
\hline 25 & 15 & 75 & & 27 & 18 & 54 & \\
\hline 29 & 24 & 58 & $174 \quad 232$ & 31 & 20 & 124 & 155 \\
\hline 33 & 22 & 66 & & 35 & 30 & 42 & \\
\hline 37 & 24 & 111 & 296 & 39 & 26 & 78 & \\
\hline 41 & 24 & 246 & 328 & 43 & 42 & 86 & 129301 \\
\hline 45 & 30 & 90 & & 47 & 30 & 141 & 470 \\
\hline 49 & 28 & 196 & & 51 & 34 & 102 & \\
\hline
\end{tabular}

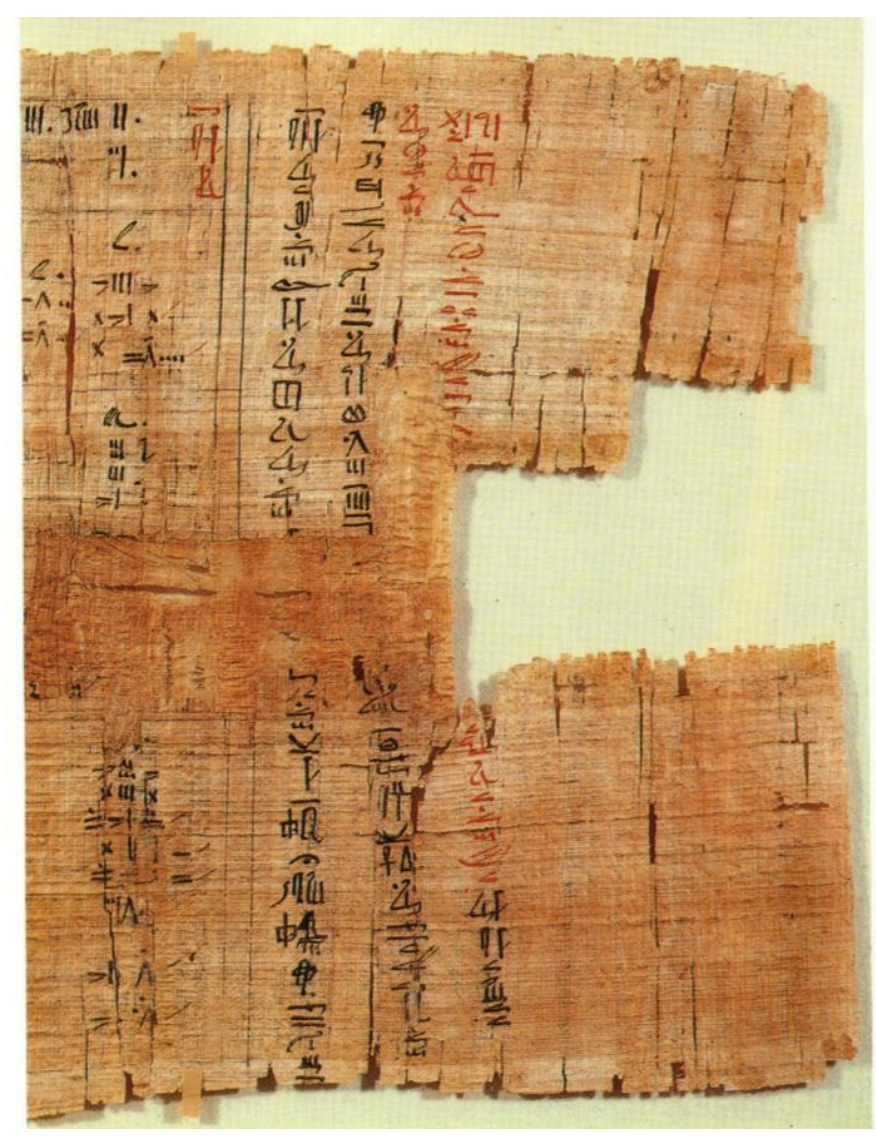

Figure 4. Doubled Fractions $\overline{3}, \overline{7}-\overline{1} \overline{5}$ [4] -10- 


\section{Problem 28}

A quantity and its $2 / 3$ are added together and from the sum $1 / 3$ of the sum is subtracted, and 10 remains. What is the quantity?

\section{Problem 29}

A quantity and its $2 / 3$ are added together, and $1 / 3$ of the sum is added; then $1 / 3$ of this sum is taken and the result is 10 . What is the quantity?

\section{Problem 30}

If the scribe says, What is the quantity of which $2 / 3 \quad 1 / 10$ will make 10 , let him hear.

\section{Problem 31}

A quantity, its $2 / 3$, its $1 / 2$, and its $1 / 7$, added together, become 33 . What is the quantity?

\section{Problem 32}

A quantity, its $1 / 3$, and its $1 / 4$, added together, become 2 . What is the quantity?

The interesting question is: why Ahmes was interested only in the $2 / \mathrm{n}$ table and not $3 / \mathrm{n}$ or $4 / 4$, etc ...? Simply because all other decompositions can be deduced easily from the $2 / \mathrm{n}$ one, or that the $2 / \mathrm{n}$ table is all what you need to produce Egyptian representations of arbitrary rational numbers. Say if you need to write $3 / 7$ in terms of Egyptian fractions, write $3 / 7=2 / 7+1 / 7$, and from Ahmes table we find $2 / 7=1 / 4+1 / 28$, and from which $3 / 7=1 / 4+1 / 7+1 / 28$, and so on. 


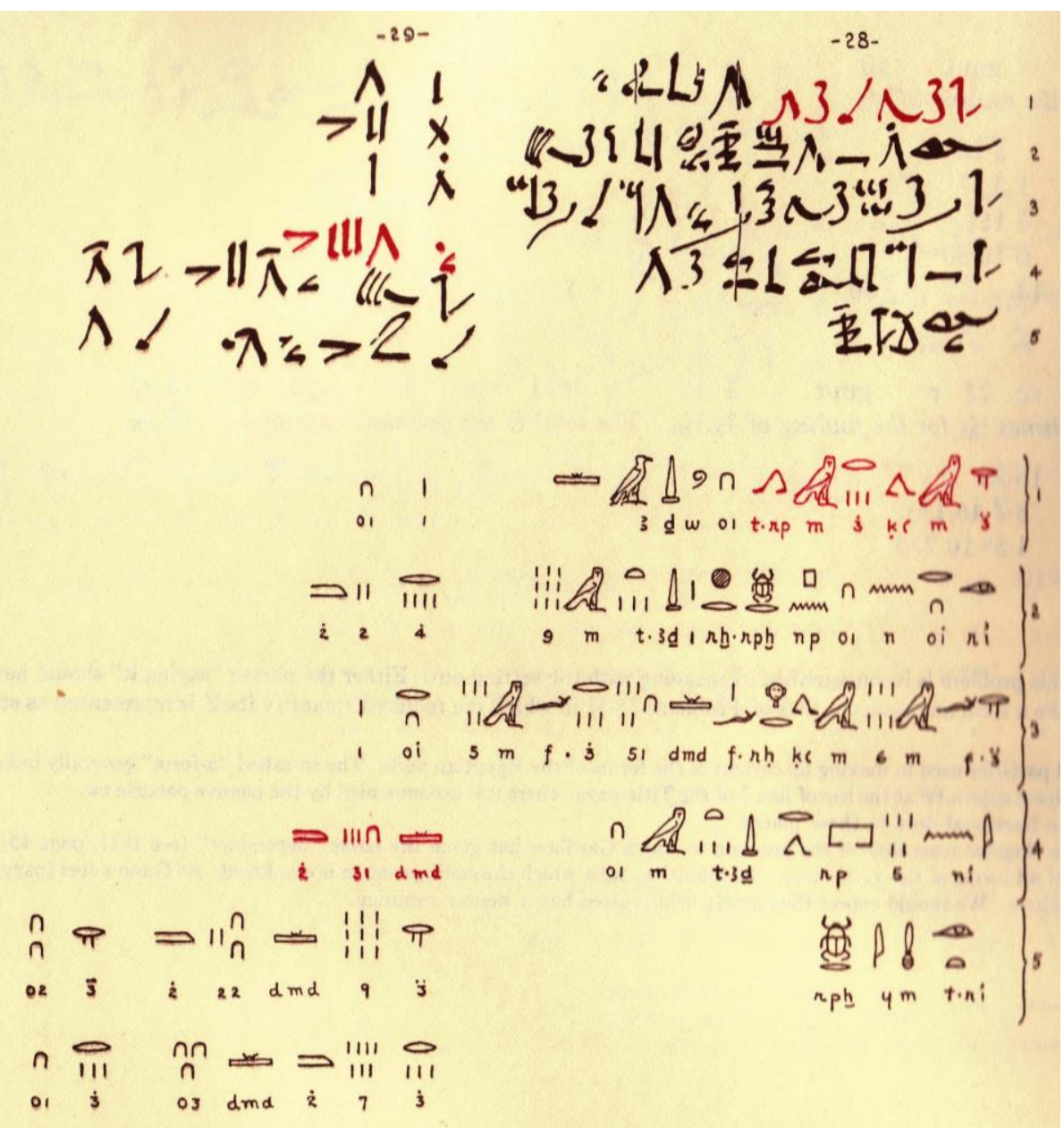

Figure 5. Plate 51, Problems 28 and 29, Rhind Papyrus.[1]

\section{How to generate Egyptian fraction?}

One can derive a good Egyptian algorithm from what so called in mathematics: "method of continued fractions". The algorithm generates reasonably few terms, and uses fractions with very small denominators.

Any real fractional number "q" can be represented as a continued fraction: 


$$
q=\frac{1}{a_{0}+\frac{1}{a_{1}+\frac{1}{a_{2}+\frac{1}{a_{3}+\frac{1}{a_{4} \ldots}}}}}
$$

in which all the values $a_{i}, \quad i=1,2,3,4, \ldots$ are integer numbers.

This terminates in a finite sequence of operations if and only if "q" is rational.

\section{Why Egyptians did use the notation $1 / n$ ?}

No one knows why the Egyptians found this style necessary.

\section{It may be for such reasons:}

Reason (1): May be they just could not find a better way.

Reason (2): May be they found it more practical for the problems that they have to solve.

Reason (3): They wrote a number $1 / \mathrm{n}$ with a mouth in the form of an oval above "n". This makes it difficult to come up with a notation $\mathrm{m} / \mathrm{n}$ without inventing completely new notation, which is always difficult.

Reason (4): This uniary fraction (i.e. fraction with unity in its numerator) comes up naturally in their method of division.

How to divide 53 by 8 ?

They would proceed as follows:

Step (1): Begin with two columns, one headed by "1" and the other by "8". Double each column until just less than 53:

$$
\begin{array}{cc}
1 & 8 \\
2 & 16 \\
4 & 32
\end{array}
$$

$-13-$ 
Step (2): Start over from the "1" and "4" and halve each number until the second column is "1".

Remark: I use the notation " $\bar{n}$ " to stand for the oval above " $n "$.

$$
\begin{aligned}
& 1 / 2=\overline{2} 4 \\
& 1 / 4=\overline{4} \quad 2 \\
& 1 / 8=\overline{8} \quad 1
\end{aligned}
$$

Step (3): Mark the numbers in the second column which add up 53.

$\begin{array}{ccc}1 & 8 & \\ 2 & 16 & * \\ 4 & 32 & * \\ \overline{2} & 4 & * \\ \overline{4} & 2 & \\ \overline{8} & 1 & *\end{array}$

The corresponding marked numbers in column "1": give you the answer:

$$
\frac{53}{8}=2+4+\overline{2}+\overline{8}, \quad \text { or } \quad 2+4+\frac{1}{2}+\frac{1}{8}
$$

Thus the notation of unary fractions, $1 / \mathrm{n}$, comes up naturally from this algorithm of division.

Reason (5): Fairness in distribution of objects between persons.

Consider the problem Ahmes follows of dividing 5 loaves of bread between 8 people.

According to our mathematics, each person will receive 0.625 piece of the bread, but in practice it is not an even division! Some have larger pieces, some have smaller.

-14- 
Ahmes calculated 5/8 as follows:

$$
\frac{5}{8}=\overline{2}+\overline{8}, \text { or } \frac{1}{2}+\frac{1}{8}
$$

which means that 4 loaves will be divided to halves, each person will receive half piece of leave, and the fifth leave will be divided to 8 parts, each one will receive one part. Thus the five loaves will be distributed evenly between the 58 persons.

Reason (6): Compare fraction numbers.

It is much easier to compare fractions using Egyptian fractions than it is by using our present-day notation for fractions! For instance: Which is bigger $5 / 8$ or $4 / 7$ ? (without using the calculator to answer it).

In fact in mathematics of nowadays, $3 / 4$ is equivalent to 0.75 , while $4 / 5$ is equivalent to 0.8 , therefore $4 / 5>3 / 4$.

Also, using the method of greatest common factor we find that $3 / 4$ is equivalent to $15 / 20$ and $4 / 5$ is equivalent to $16 / 20$, so $4 / 5>3 / 4$.

Using Egyptian fractions we write each as a sum of unit fractions:

$3 / 4=1 / 2+1 / 4$

$4 / 5=1 / 2+3 / 10$ and, expanding $3 / 10$ as $1 / 4+1 / 20$ we have

$4 / 5=1 / 2+1 / 4+1 / 20$

We can now see that $4 / 5$ is the larger by exactly $1 / 20$.

\section{Mathematical results}

Mathematicians have proved the following:

(1) Every fraction $\frac{m}{n}<1$ can be written in the form of Egyptian fractions.

(2) Each fraction can be written in an infinite number of such ways.

\subsection{Every fraction $\frac{\mathrm{m}}{\mathrm{n}}<1$ has an Egyptian fraction form}

The processes that I will present are now called greedy algorithm (since we "greedily" take the largest unit fraction we can and then repeat on the remainder). The greedy algorithm is due to the English Mathematician James Joseph Sylvester (1814 - 1897).

Idea of the method is: begin by subtracting the largest unit fraction less than the original number, then subtract the largest unit fraction less 
than the remainder, and continue the process until the remainder is a unit fraction.

Consider, for example, the presentation of $\frac{521}{1050}$ :

$\frac{1}{3}<\frac{521}{1050}<\frac{1}{2}$, then the largest unit fraction we can take away from $\frac{521}{1050}$ is $\frac{1}{3}$ and the remainder $\mathrm{R}$ is $\frac{57}{350}$.

Now $\frac{1}{7}<\frac{57}{350}<\frac{1}{6}$, then the largest unit fraction we can take away from $\frac{57}{350}$ is $\frac{1}{7}$ and the remainder $\mathrm{R}$ is $\frac{1}{50}$.

Hence $\frac{521}{1050}=\frac{1}{3}+\frac{1}{7}+\frac{1}{50}$

\subsection{Each fraction has an infinite number of Egyptian fraction} forms

Consider this fact: $\quad 1=\frac{1}{2}+\frac{1}{3}+\frac{1}{6}$

So if

$\frac{3}{4}=\frac{1}{2}+\frac{1}{4}$

By dividing the equation $(*)$ by "4" we have:

$\frac{1}{4}=\frac{1}{8}+\frac{1}{12}+\frac{1}{24}$

Hence we can rewrite $3 / 4$ in the form:

$\frac{3}{4}=\frac{1}{2}+\frac{1}{8}+\frac{1}{12}+\frac{1}{24}$

Similarly, divide the equation $(*)$ by "24" and then insert in the expression of $3 / 4$, we have

$\frac{3}{4}=\frac{1}{2}+\frac{1}{8}+\frac{1}{12}+\frac{1}{48}+\frac{1}{72}+\frac{1}{144}$,

and so on for infinite representations, every time we get a different set of unit fractions add to $3 / 4$. 


\section{Shortest Egyptian fractions}

Here I will try to list all the shortest representations of N/D (Numerator over Denominator) for D up to 11. I will use the following notation for representing the fraction in Egyptian fraction to be more readable:

For instance $4 / 5=1 / 2+1 / 4+1 / 20$, will be written in the form: $4 / 5=[2$, $4,20]$.

Here is the list for $\mathrm{N}$ from 2 up to 10 and $\mathrm{D}$ from 3 up to 11:

$2 / 3=[2,6]$

$2 / 5=[3,15]$

$2 / 7=[4,28]$

$2 / 9=[5,45]=[6,18]$

$2 / 11=[6,66]$

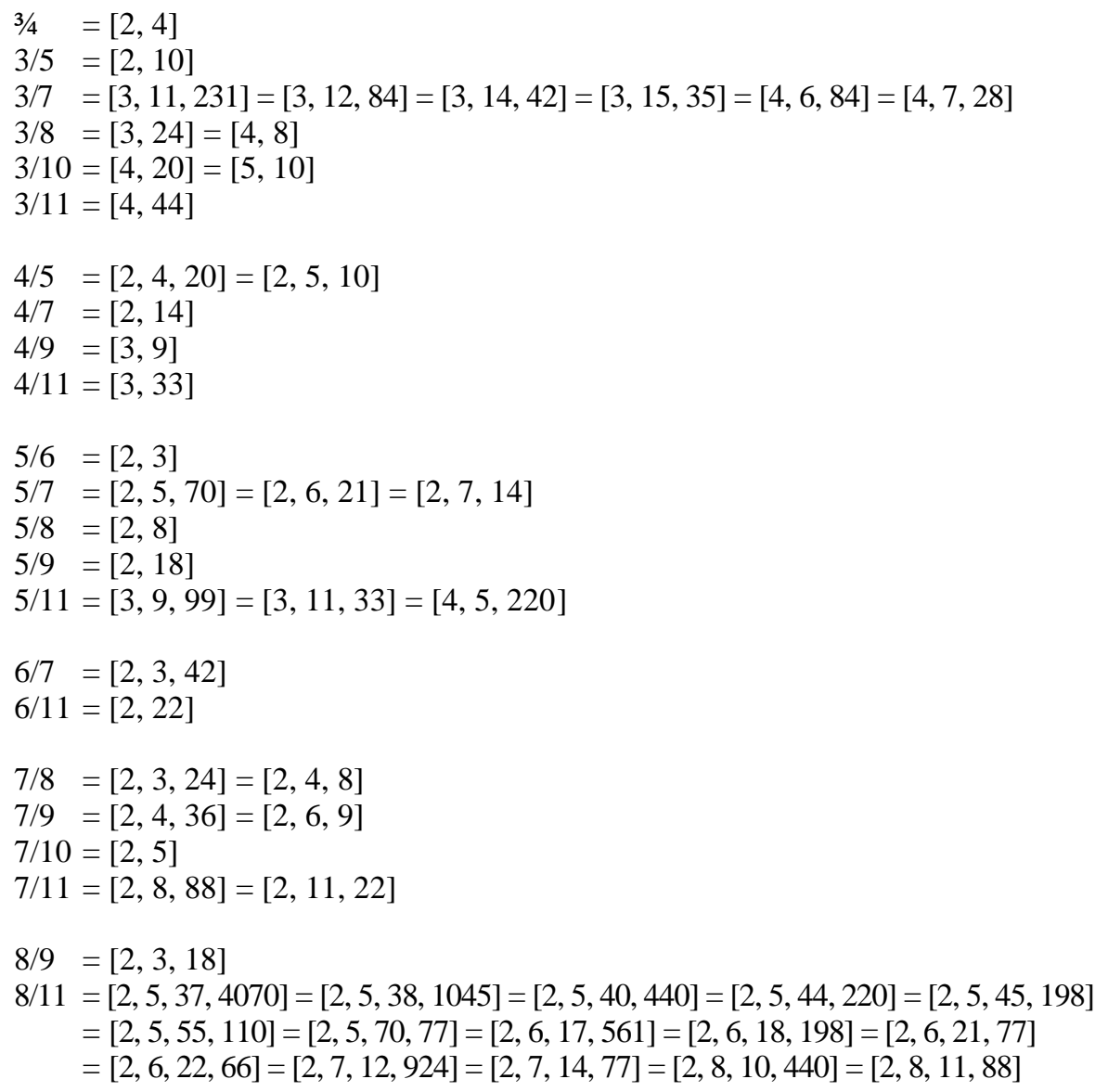

-17. 
$9 / 10=[2,3,15]$

$9 / 11=[2,4,15,660]=[2,4,16,176]=[2,4,20,55]=[2,4,22,44]=[2,5,10,55]$

$10 / 11=[2,3,14,231]=[2,3,15,110]=[2,3,22,33]$

Nowadays, mathematicians are busy with lot of problems in Egyptian fractions like:

(1) Lengths of the shortest Egyptian fractions for all the fractions N/D where the Denominator D takes all values up to 30 (say).

(2) Finding patterns for shortest Egyptian fractions.

(3) How many Egyptian fractions of shortest length are there for $\mathrm{N} / \mathrm{D}$ ?

(4) Problems of bounding the length or maximum denominator in Egyptian fraction representations.

(5) Finding expansions of certain special forms or in which the denominators are all of some special type.

(6) The fundamental trouble in solving problems concerning Egyptian fractions is the apparent random distribution of prime numbers (numbers can not be divided by any other number like: 1, 3, 5, 7, $11,13,17,19,23,29$, etc ....).

10. Horus - Eye fractions
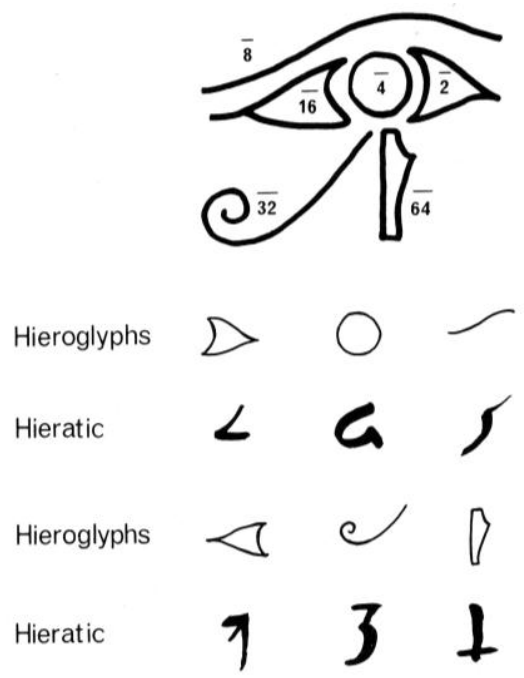

Figure 6. Horus - Eye Fractions (Middle Kingdom).[4]

-18- 
The $\overline{2}, \overline{4}, \overline{8}, \overline{1} \overline{6}, \overline{3} \overline{2}$, and $\overline{6} \overline{4}$ fractions are known as Horus - eye fractions, because they were written with different signs that resemble the 6 parts of the eye of the god Horus.

In the Egyptian mythology the eye of Horus was eaten by the fearsome god Seth.

Later it was resorted and made whole, according to the Book of the Dead, by the god Thoth, the supposed originator of mathematics, who "did this with his fingers".

The $\overline{2}, \overline{4}, \overline{8}, \overline{1} \overline{6}, \overline{3} \overline{2}, \overline{6} \overline{4}$ Hours - eye fractions in modern terminology for a convergent geometrical series of 6 terms, with sum of $1-1 / 64$, and its sum to infinity is 1 , showing that the series itself was short from 1 by $\overline{6} \overline{4}$.

If the Horus - Seth - Thoth story really had a mathematical connection, it could be that the damaged Horus - eye was magically made whole by the restoration of the missing $\overline{6} \overline{4}$.

RMP no. 79 makes it clear that the Egyptians were familiar with such series [4].

\section{Results and conclusions}

In the present paper we present six different Ancient Egyptian Documents that recorded all the calculations of the Egyptian fractions. The RMP is the most extensive mathematical source - book that survives from ancient Egypt, but the knowledge of the ancient Egyptians in mathematics is much greater than was recorded in different documents; one cannot expect the full range of knowledge to be apparent in a learner's text.

Egyptians knowledge in mathematics for sure date back to, at least, Old Kingdom days, at least to the age of the stone pyramid builders. 
Also we gave six different reasons that forced the Ancient Egyptians to apply the Egyptian fractions in their daily calculations. Also we illustrated the Egyptian way for dividing the rational number. At the end we presented one of very interesting applications in Egyptian fractions which is the "Hours - Eye fractions", and in nowadays mathematics the series of the Hours - Eye fractions represent a convergent geometric series.

Little could the ancient Egyptians know that their simple table of fractions could thousands of years later be the subject of so much research. It seems to be the subject of research for many years to come, even in the existence of high speed computers!

The Greeks often proclaimed their mathematical debt to Egypt. Proclus in his "Commentary on Euclid", following Herodotus, wrote that geometry had an Egyptian origin arising out of the necessity of resurveying the land after each inundation.

Aristotle "Metaphysics I", on the other hand, attributed the birth of mathematics in Egypt to the existence of a priestly leisured class.

We come to conclusion that the Ancient Egyptians were very brilliant indeed in using the system of Egyptian fractions in their daily life, not only that but we can consider them without any sort of exaggerations as the fathers of the "theory of numbers" as well as "geometry".

At the end I would like to add that history of science can provide tools so that students will be able to achieve scientific concepts successfully. In 2003 John Heilborn said in the conference "History as a collaborator of Science", that was held in the Center of Study of History of Sciences (CEHIC) at the Universitat Autonoma of Barcelona, "Historical material should have a prominent place in the pedagogy of Science; but not to recall the past for itself, or for anecdotes or sugar coating, but because, for some purposes, History may be the best way to teach Science" [6]. 


\section{References}

[1] A. Chaca, "The Rhind Mathematical Papyrus". Classics in Mathematics Education, A series, Volume 8. The National Council of Teachers of Mathematics, (Virginia 1978).

[2] T. E. Peet, "Mathematics in ancient Egypt". Bulletin of the John Rylands Library 15 (1931), 409 - 441.

[3] R. J. Gillings, "What is the relation between the EMLR and the RMP recto?" Journal of Archives for History of exact sciences 14 (\# 3) (1975) 159 - 167.

[4] G. Robins and C. Shute, "The Rhind Mathematical Papyrus - an ancient Egyptian text" Dover Publications, Inc. (New York 1990).

[5] R. J. Gillings, "Mathematics in the Time of the Pharaohs" (1972), reprinted 1982 (reviewed by M. Bruckheimer and Y. Saloman. Historia Mathematica 4 (1977), 445 - 452).

[6] R. Massa, F. Romero, and I. Guevara, "Teaching mathematics through history: Some trigonometric concepts". Proceeding of the second ICESHS (Cracow, Poland) September 6-9, (2006)150 157.

\section{Suggested readings}

(a) E. M. Bruins, "Ancient Egyptian arithmetic: 2/n". Indagationes mathematicae 14 (1952), 81 - 91.

(b) A. B. Chace, L. Bull, H. P. Manning, and R. C. Archibald, "The Rhind Mathematical Papyrus". Mathematical Association of America, Vol. 1 (1927), Vol. 2 (1929), reprinted 1979.

(c) S. R. K. Glanville, "The Mathematical Leather Roll in the British Museum" Journal of Egyptian Archaeology 13 (1927), 232 - 238.

(d) B. L. van der Waerden, "The (2: n) table in the Rhind Papyrus". Centaurus 23 (1980), $259-274$.

(e) K. Gong, "Egyptian Fractions". University of Berkeley (1992).

(f) P. Campbell, "A practical approach to Egyptian fractions". Journal of Recreational Mathematics 10 (1977 - 1978) 81 - 86.

(g) P. Erdös and E. Straus, "Representation of 1 by Egyptian fractions". American Mathematical Monthly 78 (1971) 302. 
(h) E. Kiss, "Remarks on the representation of fractions between 0 and 1 as the sum of unit fractions". Acad. R. P. Romine Fil. Cluj Stud. Cerc. Mat. 11 (1960) 319 - 323.

(i) G. Tenenbaum and H. Yokota, "Length and Denominators of Egyptian fractions. III". Journal of Number Theory 35 (1990) 150 $-156$.

(j) M. D. Vose, "Egyptian fractions". The Bulletin of the London Mathematical Society 17 (1985) $21-24$.

(k) H. Yokota, "Length and Denominators of Egyptian fractions". Journal of Number Theory 24 (1986) $249-258$.

(1) H. Eves, "An Introduction to the History of Mathematics". Holt, Reinhardt, and Winston, 1953.

(m) C. B. Boyer, "A history of mathematics". John Wiley \& Sons Inc., New York, second edition (1989).

(n) O. Ore, "Number theory and its history". McGraw Hill (1948).

(o) O. Neugebauer, "The exact sciences in antiquity". Dover, Second edition (1969).

(p) M. Gardner, "The Egyptian Mathematical Leather Roll, attested short term and long term" in Ivor Gratton - Guiness (ed.). History of the Mathematical Sciences. Hindustan Book Co. (2002).

(q) W. R. Knorr, "Techniques of fractions in ancient Egypt and Greece". Historia Mathematica 9 (1982) 133 - 171.

(r) B. M. Stewart, "Sums of distinct divisors". American Journal of Mathematics 76 (\# 4) (1954) 779 - 785. 